\title{
A Phenomenological Study on the Synergistic Role of Precious Metals in the Steam Reforming of Logistic Fuels on Trimetal-Supported Catalysts
}

\author{
Abdul-Majeed Azad and Desikan Sundararajan \\ Chemical Engineering Department, The University of Toledo, 2801 W. Bancroft Street, Toledo, OH 43606-3390, USA \\ Correspondence should be addressed to Abdul-Majeed Azad, Abdul-Majeed.Azad@Utoledo.Edu
}

Received 24 August 2010; Accepted 12 October 2010

Academic Editor: Meilin Liu

Copyright (C) 2010 A.-M. Azad and D. Sundararajan. This is an open access article distributed under the Creative Commons Attribution License, which permits unrestricted use, distribution, and reproduction in any medium, provided the original work is properly cited.

Fuel processors are required to convert sulfur-laden logistic fuels (jet fuels, diesel, and coal) into fuel cell quality hydrogen-rich reformate with little or no sulfur for extended periods. Sulfur poisons and deactivates the reforming catalyst, therefore, sulfurtolerant catalysts ought to be developed. In this paper, the development, characterization, and evaluation of a series of nanoscale ceria-supported reforming catalysts containing three noble metals in low concentration ( $1 \mathrm{wt} \% \leq$ total metal loading $\leq 1.33 \mathrm{wt} \%$ ) for the steam-reforming of kerosene (a JP-8 surrogate) are reported. Their performance is quantified in terms of $\mathrm{H}_{2}$ yield, tolerance towards sulfur in the fuel, and the on-stream stability and compared with that of monometal and bimetal analogs under identical conditions. Due to the inherent cooperative synergy, a trimetal catalyst was found far superior to its mono- and bimetallic analog containing same amount of the precious metal loading in terms of quality of the reformate (measured by $\mathrm{H}_{2}$ level in steady-state) as well as the catalyst longevity on-stream prior to deactivation. At the same time a mechanistic correlation between the distinct role of a given precious metal and the extent of its loading in each of the formulations and quality of the corresponding desulfurized $\mathrm{H}_{2}$-rich reformate was discovered.

\section{Introduction}

The catalysts used for obtaining a hydrogen-rich reformate logistic fuels are severely poisoned by the sulfur present in them. During reforming organosulfur in the fuel stream gets transformed into $\mathrm{H}_{2} \mathrm{~S}$, even $1 \mathrm{ppm}$ or less of which the reformate could deactivate the SOFC anode rapidly [1]. Thus, novel fuel processors are required to convert logistic fuels into hydrogen-rich reformate for extended periods and deliver hydrogen with little or no sulfur to the fuel cell stack. In order to facilitate continuous and uninterrupted operation of logistic fuel processors, they must incorporate robust sulfur-tolerant catalysts.

To respond to this key requirement, a systematic investigation was undertaken to develop and use a family of 10 formulations: 3 containing one, 3 containing two, and 4 containing as many as three precious metals in them. The active metal dispersion in these sulfur-tolerant catalyst formulations was varied between 1 and $1.33 \mathrm{wt} . \%$. For example, in the case of single metal-containing catalysts the precious metal loading was $1 \mathrm{wt} \%$. In the case of formulations containing a combination of two noble metals, $1 / 2 \mathrm{wt} \%$ of each was added. In the case of three-metal series, in one instance $1 / 3 \mathrm{wt} \%$ of each of the three noble metals were used while in the remaining cases, $1 / 2 \mathrm{wt} \%$ of each of the two and $1 / 3 \mathrm{wt} \%$ of the third metal was used in rotation. The goal was to understand the role of precious metals in imparting sulfur-tolerance to the nanoscale ceria-based reforming catalysts in the process of hydrogen generation via steam reforming.

These formulations were assessed in terms of their sulfurtolerance, phase integrity, and the quality of reformate from kerosene (JP-8 surrogate) fuel at temperatures typically employed in reforming. The performance of monometal and bimetal-supported nanocatalysts in the steam reforming of a JP-8 surrogate fuel (kerosene) containing $260 \mathrm{wppm}$ $(260 \mathrm{mgS} / \mathrm{kg}$ fuel) has been recently reported $[2,3]$. These investigations revealed several multifunctional aspects 
towards their effectiveness in $\mathrm{H}_{2}$ generation in terms of high yield and long-term stability on stream and the crucial role of the ceria support in rendering the catalyst sulfur-tolerant as a whole. Furthermore, the catalyst deactivation appeared to be mainly due to sulfur poisoning rather than carburization (coke formation).

This communication is the third in the series that highlights the performance of trimetal-supported ceria catalysts in terms of hydrogen yield and sulfur-tolerance as a function of time on-stream. Clearly, the trimetal dispersion on nanoscale ceria support proved to be superior to its mono- and bimetal analogs both, in terms of the longevity of the steady-state, hydrogen yield, and sulfur tolerance, under identical experimental conditions. A plausible mechanistic correlation between the synergistic role of precious metals in presence of one another and the behavior of these catalysts in terms of the above-mentioned features is suggested.

\section{Experimental Details}

Nanoscale support material consisting 10 mole\% gadolinia$\left(\mathrm{Gd}_{2} \mathrm{O}_{3}{ }^{-}\right)$doped $\mathrm{CeO}_{2}$ - hereafter referred to as $\mathrm{GDC}$ - was synthesized via ammonia precipitation using appropriate water soluble precursors for cerium and gadolinium (from Alfa-Aesar, MA) followed by hydrothermal treatment of the basic slurry thus obtained, in an autoclave at $240^{\circ} \mathrm{C}$, for 2 hours. The resulting material was dried overnight and systematic structural and morphological characterizations were carried out to follow the crystallization and phase evolution pathways as a function of calcination temperaturetime profile.

A total of four formulations were developed by dispersing precious metals - three at a time-onto the GDC support material, using their respective water soluble precursors: ruthenium (III) chloride (99.999\%), palladium (II) nitrate (99.95\%), and rhodium (III) nitrate hexahydrate (99.999\%), all from Alfa-Aesar, MA. For this purpose, aqueous slurry of GDC and the precious metal precursors was homogenized in a rotary evaporator for 4-6 hours and the thickened mass was dried overnight in a vacuum oven at $100^{\circ} \mathrm{C}$. The dried cake consisting of soft agglomerates was crushed using mortar and pestle and pulverized in a ball mill using 2-propanol and $5 \mathrm{~mm}$ diameter zirconia media. The ball-milled slurry was dried again under ambient conditions and sieved through 325 mesh screen. Each formulation was calcined in air at $700^{\circ} \mathrm{C}$ for 2 hours. These formulations contained $(1 / 3 \mathrm{wt} \%$ $\mathrm{Ru}+1 / 3 \mathrm{wt} \% \mathrm{Pd}+1 / 3 \mathrm{wt} \% \mathrm{Rh})$ in one case, $(1 / 3 \mathrm{wt} \% \mathrm{Ru}$ $+1 / 2 \mathrm{wt} \% \mathrm{Pd}+1 / 2 \mathrm{wt} \% \mathrm{Rh})$ in the second, $(1 / 2 \mathrm{wt} \% \mathrm{Ru}+$ $1 / 3 w t \% \mathrm{Pd}+1 / 2 \mathrm{wt} \% \mathrm{Rh})$ in the third, and $(1 / 2 \mathrm{wt} \% \mathrm{Ru}+$ $1 / 2 \mathrm{wt} \% \mathrm{Pd}+1 / 3 \mathrm{wt} \% \mathrm{Rh})$ in the fourth case, the remaining being GDC. They will be referred to as RPR333, RPR322, RPR232, and R223, respectively. In this assignment, the first $\mathrm{R}$ refers to the noble metal $\mathrm{Ru}$ and the second $\mathrm{R}$ to $\mathrm{Rh} ; \mathrm{P}$ stands for Pd.

The catalysts were characterized by a host of techniques with respect to their crystallinity, active metal dispersion, and structural and morphological features. Temperatureprogrammed reduction (TPR) of the as-prepared reforming catalysts was conducted using Micromeritics AutoChem 2910 (Norcross, GA), to optimize a systematic activation protocol for each catalyst prior to sulfidation and reforming experiments.

Independent sulfidation experiments were carried out by introducing $1000 \mathrm{ppm} \mathrm{H}_{2} \mathrm{~S}$-balance nitrogen stream over a bed of $1 \mathrm{~g}$ of powder catalyst at $800^{\circ} \mathrm{C}$ for 4 and 24 hours. X-ray powder diffraction (XRD) signatures on the as-prepared and postsulfided samples were collected on a Philips diffractometer (PW 3050/60 X'pert Pro), using monochromatic $\mathrm{CuK} \alpha_{1}$ radiations $(\lambda=1.54056 \AA)$ and $\mathrm{Ni}$ filter. The total amount of sulfur retained by the catalysts was quantified by wet chemical techniques by NSL Analytical, Cleveland, $\mathrm{OH}$.

Steam-reforming experiments were carried out on powder samples ( $1 \mathrm{~g}$ ) using kerosene as the fuel. LC-MS test established the sulfur content of this kerosene sample to be $260 \mathrm{ppm}$ as determined by Paragon Laboratories, MI. The packed-bed reactor used here was a quartz tube, 19inch long and 1-inch OD. The catalyst was packed in a stainless steel filter with $5 \mu \mathrm{m}$ size pore from Swagelok. The filter containing the catalyst was placed in the center of the reactor and plugged with loosely packed quartz wool. The quartz reactor was then placed in a 1-inch. split tube furnace equipped with a PID controller.

Water and fuel (kerosene) were pumped into the reactor with ChromTech, Inc. ISO-100 high precision HPLC pumps. Argon was used as a sweep gas for the reforming reaction. The steam to carbon ration $(\mathrm{S} / \mathrm{C})$ was maintained at 3 . The flow rates of water and fuel were adjusted to maintain a constant space velocity in the reactor at $65,000 \mathrm{~h}^{-1}$. The feed stream containing sweep gas, water, and fuel was first introduced into a preheater (vaporizer furnace) operated at $250^{\circ} \mathrm{C}$ to ensure complete vaporization of the feed. This temperature is based on the physical properties of kerosene to ensure complete vaporization without cracking. All reforming reactions were carried out at $800^{\circ} \mathrm{C}$. The product stream coming out of the reactor was drawn into a condenser to separate the liquid and gas products. The liquid fraction consisted mainly of water and unreacted fuel with traces of other liquid hydrocarbons. The composition of the gas reformate mixture was analyzed via Gas Chromatograph (GC). Shimadzu GC, Model 2010, equipped with pulsed discharge helium ionization detector (PDHID) and flame photometric detector (FPD) was used to analyze the gas products. The FPD on the GC was facile in detecting sulfur species in the reformate stream. The duration of the experiment was determined by the stability and activity exhibited by the catalysts on stream. The hydrogen yield was defined as

$$
\text { \%yield }=\frac{\left(F_{i}\right)}{\left(\nu_{i}\right) \cdot\left(F_{j, 0}\right)} * 100,
$$

where $F_{i}$ is the moles of species $i$ produced per min, $v_{i}$ is the stoichiometric coefficient of species $i$, and $F_{j, 0}$ is the molar flow rate of the reactant in moles/min.

The GC was calibrated with respect to hydrogen, carbon monoxide, carbon dioxide, and methane-the major 


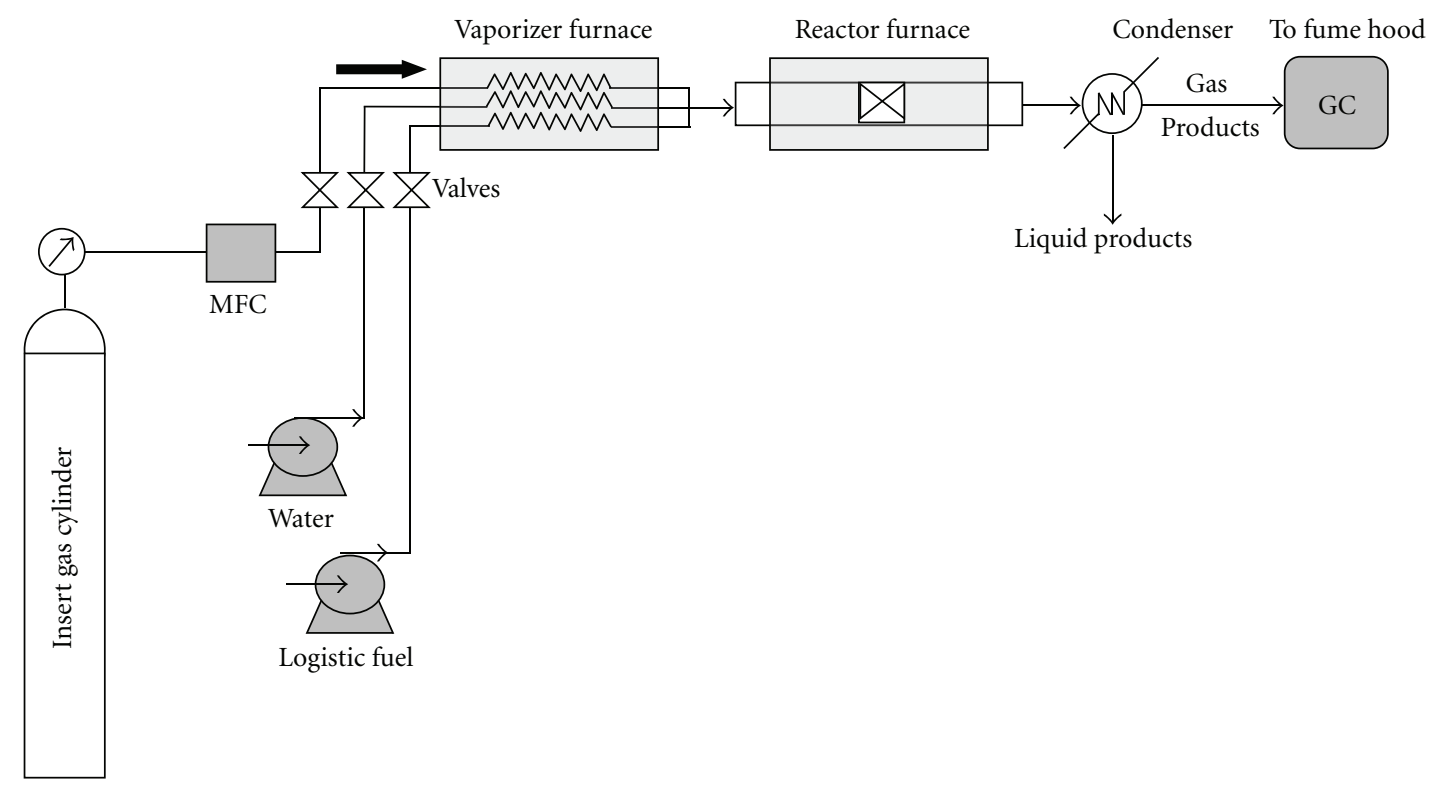

FIgURE 1: Schematic of the set-up for reforming experiments.

constituents in a typical reformate-over a wide range of concentrations. GC was also calibrated with respect to $\mathrm{H}_{2} \mathrm{~S}$ concentration between zero and $1000 \mathrm{ppm}$. The reforming was conducted over extended period of time. It was terminated as per an arbitrarily selected criterion of hydrogen yield reducing to $20 \%$ or the sulfur level reaching $50 \mathrm{ppm}\left(\right.$ as $\left.\mathrm{H}_{2} \mathrm{~S}\right)$ in the exit stream. Concentration of other gases was also monitored simultaneously as a function of time.

Systematic microstructural analysis was performed by scanning electron microscopy (SEM-Phillips XL $30 \mathrm{FEG}$ ) and transmission electron microscopy (TEM-JEOL 3011). Both these techniques are equipped with the capability of performing energy dispersive X-ray spectroscopy (EDS) as well. The SEM is equipped with Rutherford's back scattering electron mapping (RBSE) as well. The chemical state analysis of the active components in the postreformed samples was performed by using X-ray Photoelectron Spectroscopy on the Kratos Axis Ultra XPS.

Figure 1 shows a schematic of the set-up used for the reforming experiments.

\section{Results and Discussion}

3.1. Rationale behind the Choice of Ceria. Alumina $\left(\mathrm{Al}_{2} \mathrm{O}_{3}\right)$ has become a universal support for a number of catalysts in oil refining due to its high thermal and chemical stability. However, there is a great deal of historic as well as strategic rationale for using ceria support in the present work. Ceria is commercially used in catalytic converters as a support for three-way catalyst for reducing harmful emissions from automobiles [4]. It is well known for its high oxygen storage capacity (OSC) and easy reducibility due to its facile $\mathrm{Ce}^{\mathrm{III}} \leftrightarrow \mathrm{Ce}^{\mathrm{IV}}$ equilibrium [5-8]. $\mathrm{CeO}_{2}$-based materials are quite active and stable both in reducing and in oxidizing atmospheres in high-temperature regimes compared to other conventional support systems. This, in conjunction with a preparative technique that provides nanoscale particles, results in a high-surface-area catalyst with the possibility of high activity for the reforming of sulfur-laden fuels. When used as a support for precious metal(s), it results in the transfer of oxygen to the supported metals while the support is then reoxidized by the water present in the steam reforming reaction. Increased OSC leads to increase in oxygen vacancies which contribute to increased reducibility of ceria as well. Although $\mathrm{CeO}_{2}$ is more active as a reforming catalyst than $\mathrm{Ce}_{2} \mathrm{O}_{3}$, it can act beneficially towards sulfur tolerance as will be shown later.

Thermodynamically, in a reducing environment $\mathrm{Ce}_{2} \mathrm{O}_{3}$ has higher sulfidation equilibrium constant than $\mathrm{CeO}_{2}$, suggesting a possibility of formation of either cerium oxysulfide (partial sulfidation) or cerium sesquisulfide (complete sulfidation). This mechanism might help mitigate sulfurmediated poisoning and deactivation of ceria-based catalysts in the long run. This sacrificial role may also allow precious metal(s) to remain active longer, resulting in better catalyst life. Furthermore, $\mathrm{H}_{2} \mathrm{~S}$ adsorption on ceria is partially reversible. The thermodynamics of the $\mathrm{CeO}_{2}-\mathrm{H}_{2} \mathrm{~S}$ reaction, however, do not allow the reduction of $\mathrm{H}_{2} \mathrm{~S}$ to below $200 \mathrm{ppm}$ at about $627^{\circ} \mathrm{C}$; even at a temperature of $827^{\circ} \mathrm{C}$, the $\mathrm{H}_{2} \mathrm{~S}$ level cannot be reduced to below $100 \mathrm{ppm}$. This requires ceria to be in a reduced form $\left(\mathrm{CeO}_{n} ; n<2\right)$ to achieve the removal of sulfur to desired levels. Upon reduction, $\mathrm{CeO}_{2}$ goes to $\mathrm{Ce}_{2} \mathrm{O}_{3}$, thereby creating oxygen ion vacancies, and thus sulfidation of ceria occurs rapidly. In the light of these characteristics, ceria was used as a support matrix for the development of sulfurtolerant catalytic formulations [9-11].

3.2. "Prior-to-Use" Catalyst Activation. Prior to their use in reforming, it is necessary to bring the catalysts to their most 


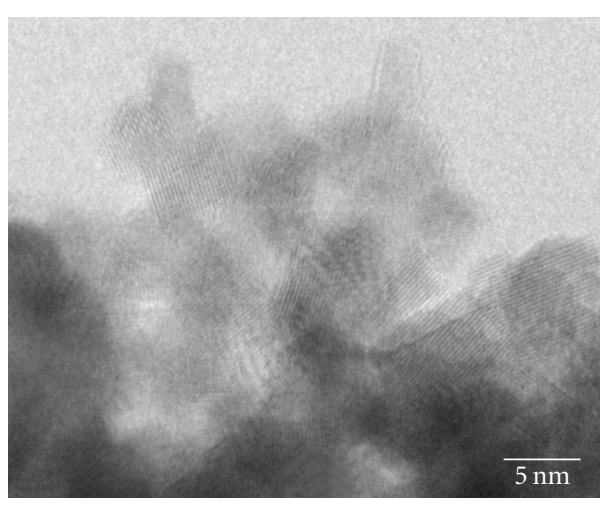

(a)

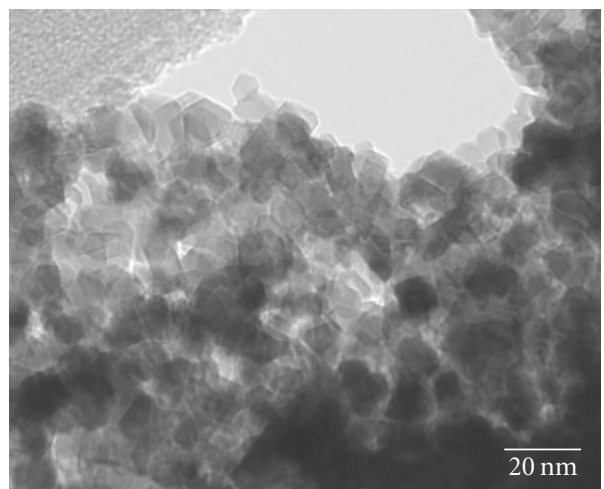

(c)

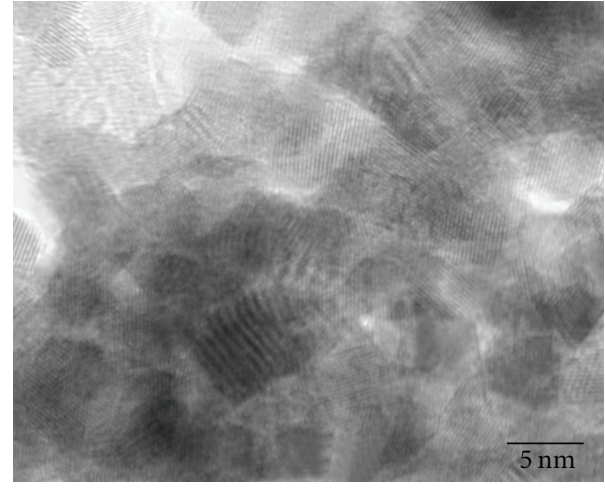

(b)

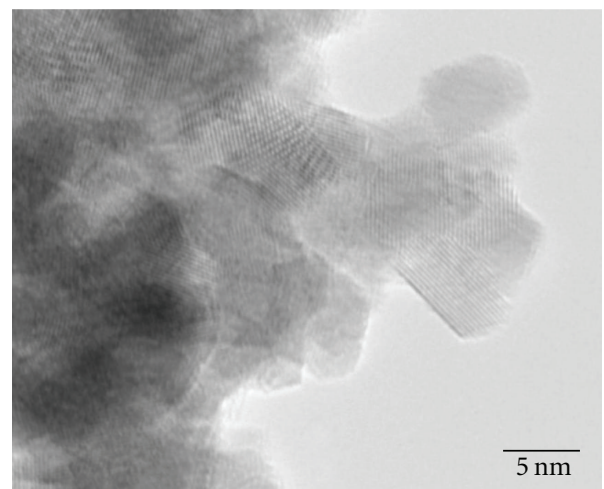

(d)

FIGURE 2: TEM images of the as-prepared trimetallic catalysts: (a) RPR333, (b) RPR322, (c) RPR232, and (d) RPR223.

active form. An activation protocol was established by using the technique of temperature-programmed reduction (TPR) using the Micromeritics 2910 instrument (Norcross, GA). The amount of sample used in all the TPR experiments was kept constant at $0.1 \mathrm{~g}$. Very interesting features in terms of the location and magnitude of the TPR were discerned for the entire series. While the peak position indicates the approximate temperature around which the reduction ought to be carried out to activate the catalyst, the area under the peaks signifies the amount of hydrogen required for the reduction of the corresponding noble metal(s) in the catalyst.

Notably, two distinct peaks were present in the TPR profiles of all the catalysts (mono-, bi-, and trimetallic): the first one occurred in the window of $140-170^{\circ} \mathrm{C}$, indicating that the reduction of any oxygen, adsorbed or chemically bonded to the noble metal(s), was complete at or below $170^{\circ} \mathrm{C}$. There was a second hump-like peak around $300^{\circ} \mathrm{C}$ which is possibly due to the reduction of cerium oxide $\left(\mathrm{CeO}_{2}\right)$ to cerium sesquioxide $\left(\mathrm{CeO}_{1.5}\right)$. Moreover, the amount of hydrogen up-take necessary to activate (reduce) the noble metal in a given catalyst was commensurate with the noble metal fraction in it, as can be readily seen from the TPR results summarized in Table 1 on all the ten catalyst formulations.
3.3. Structural and Microstructural Artifacts of the Precious Metal-Supported Nanocatalysts. The TEM images of the asprepared tri-metal catalysts are shown in Figure 2; clearly all formulations possess nanofeatures. The contrasting light and dark particle contours in these images belong to the GDC support and the noble metals, respectively. This further suggests that despite low concentration, the dispersion of the noble metals is highly uniform throughout the matrix.

Thus, the preparatory technique utilized for making them is quite effective in yielding uniform distribution of the precious metals throughout the support. The nanofeatures observed in the TEM images were corroborated by the broad diffraction peaks in their respective XRD patterns (not shown here) as well. The gross XRD patterns are typical of those for $10 \mathrm{~mole} \%$ gadolina-doped ceria (GDC) used in this work [12]. The peaks for the noble metals were not discernable due to their low loading (total noble metal loading $\leq 1.33 \mathrm{wt} \%$ ) which is below the detection limit of the XRD technique. The crystallite size estimated using Scherrer's equation yielded values in the range of 5-8 nm, which is in excellent agreement with those seen in the TEM images. These nanofeatures ensure large surface area and effective noble metal dispersion in these formulations. This in turn lowers the loading and keeps the manufacturing cost low without compromising reforming performance. 


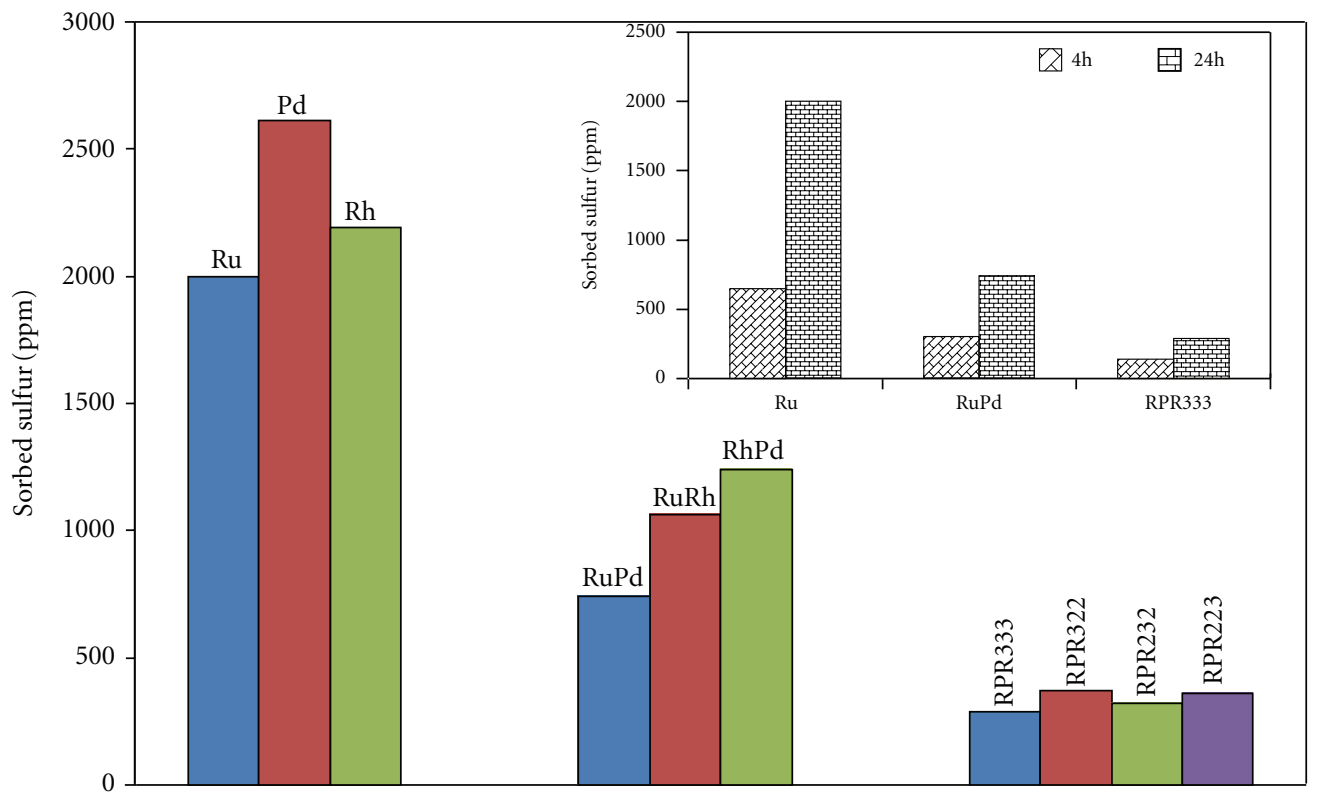

Figure 3: Comparison of sulfur-sorption characteristics of trimetallic catalysts during 24 hours soak at $800^{\circ} \mathrm{C}$ in $1000 \mathrm{ppm} \mathrm{H}_{2} \mathrm{~S} / \mathrm{bal}$. $\mathrm{N}_{2}$ ambient, with those of mono- and bi-metal analogs. Inset: sulfur sorption profiles of three typical catalysts (one from each series) during 4 and 24 hours soak time.

3.4. Propensity to Sulfur Tolerance. Recent studies have shown irreversible sulfur poisoning to be the main cause of deactivation of reforming catalyst in the case of logistic fuels [1], making it imperative that the catalysts designed for reforming of sulfur-laden fuels be evaluated for their sulfur tolerance first. Therefore, as was done in the case of mono- and bi-metal-supported formulations, the trimetal catalysts were also examined for their sulfur tolerance and phase integrity under conditions of sulfur exposures for extended period. Packed beds of the catalyst powders $(1 \mathrm{~g})$ were exposed to stream containing $1000 \mathrm{ppm} \mathrm{H}_{2} \mathrm{~S}$ in nitrogen for 4 and 24 hours, and the postsulfided samples were analyzed for sulfur pick-up.

The trend of sulfur pick-up by these formulations showed an interesting pattern. First and foremost, and as expected, it was found to be proportional to the soak-time: more sulfur was sorbed by sample in 24 hours than in 4 hours. Second, the amount of sorbed sulfur decreased progressively as the number of noble metals increased, without increasing their percentage appreciably. For example, it was found that the amount of sulfur scavanged by the bimetallic series was considerably lower [3] than that in the case of single metal dispersion [2], which decreased further in the case of trimetallic series.

In the 24-hour soak experiments, RuGDC picked up 2000 ppm while PdGDC and RhGDC sorbed 2610 and 2190 ppm, respectively. Thus, in the case of monometal formulations, ruthenium-based formulation exhibited highest sulfur tolerance followed by the rhodium analog; palladiumbased formulation was most susceptible to sulfur poisoning, meaning that the sulfidation susceptibility followed the pattern: $\mathrm{Ru}<\mathrm{Rh}<\mathrm{Pd}$.
In the bi-metal series, the amount of sulfur sorbed was 740, 1060, and $1240 \mathrm{ppm}$ by RuPd (1/2 wt $\% \mathrm{Ru}+1 / 2 \mathrm{wt} \%$ $\mathrm{Pd})$, RuRh (1/2 wt $\% \mathrm{Ru}+1 / 2 \mathrm{wt} \% \mathrm{Rh})$, and RhPd (1/2 wt $\%$ $\mathrm{Pd}+1 / 2 \mathrm{wt} \% \mathrm{Rh})$, respectively. Similar trends were evident in trimetallic formulations; the amount of sulfur sorbed by RPR333, RPR322, RPR232, and RPR223 was 290, 370, 320, and $360 \mathrm{ppm}$, respectively. Thus, RPR333 (1/3 wt $\% \mathrm{Ru}+$ $1 / 3 w t \% \mathrm{Pd}+1 / 3 w \mathrm{t} \% \mathrm{Rh})$ showed the smallest sulfur pickup. RPR322 (1/3wt\% Ru + 1/2wt $\% \mathrm{Pd}+1 / 2 \mathrm{wt} \% \mathrm{Rh})$ and RPR223 (1/2wt\% Ru + 1/2wt\% Pd + 1/3wt\% Rh) showed higher sulfur sorption amongst the series. This could be attributed to the higher level $(1 / 2 \mathrm{wt} \%)$ of palladium in them as opposed to $1 / 3 \mathrm{wt} \%$ in RPR333 and RPR232.

Thus, the strong resistance to sulfur by ruthenium followed by rhodium and then palladium (least resistant) is manifested in all the combinations. This is shown in Figure 3 for 24-hour soak time. The inset compares the sulfur pick-up trend by one catalyst from each series during 4- and 24-hour soak time.

We will examine this trend and its correlation with the steam-reforming capability of tri-metal-supported catalysts subsequently.

Figure 4 shows the TEM images of the trimetallic catalysts after sulfidation for 24 hours at $800^{\circ} \mathrm{C}$ in a nitrogen stream containing $1000 \mathrm{ppm}_{2} \mathrm{~S}$.

As can be seen from Figure 4, there is evidence of slight grain growth in the sulfided samples. Moreover, the particles do show some agglomeration as well.

In order to ascertain that the phase and microstructural integrity of the catalysts under sulfidation conditions was not compromised, the postsulfided samples were subjected to Xray diffraction, and their patterns are shown in Figure 5. 


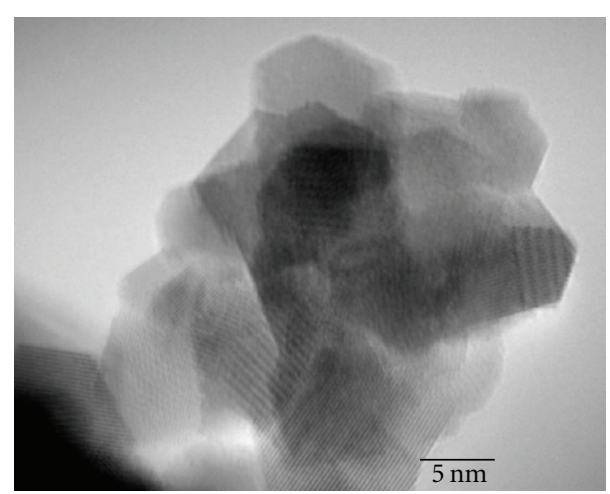

(a)

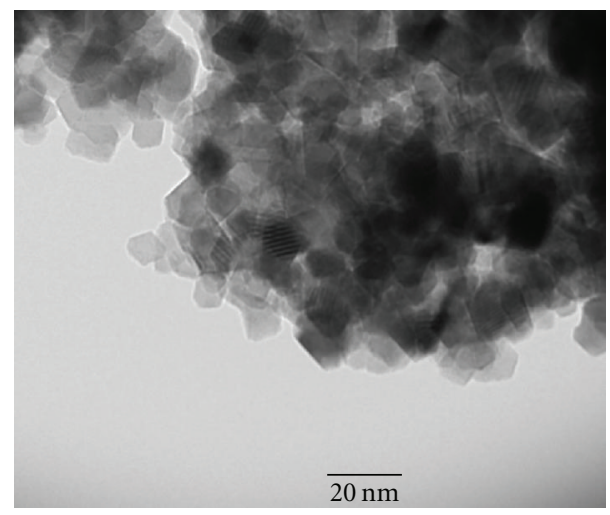

(c)

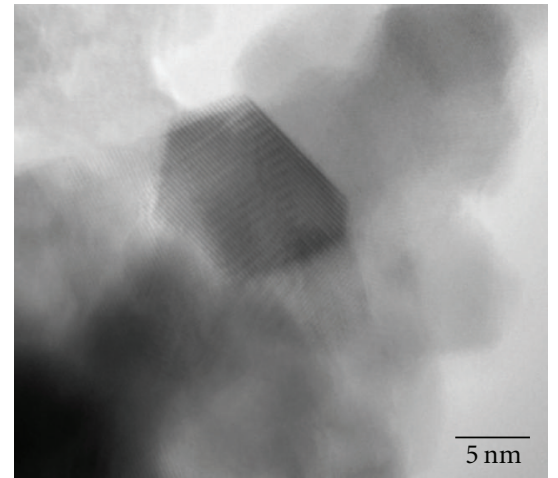

(b)

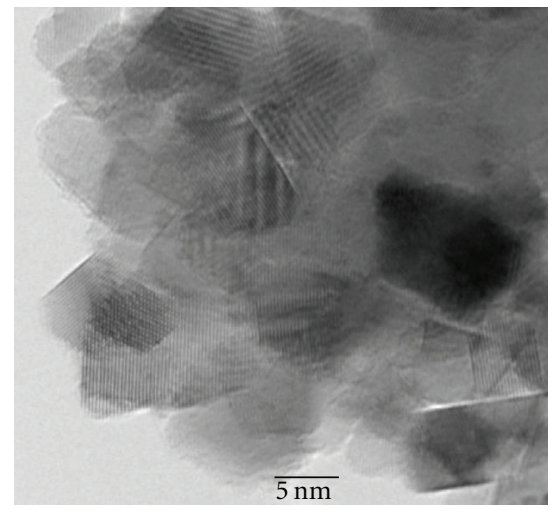

(d)

Figure 4: TEM images of the sulfided catalysts: (a) RPR333, (b) RPR322, (c) RPR232, and (d) RPR223.

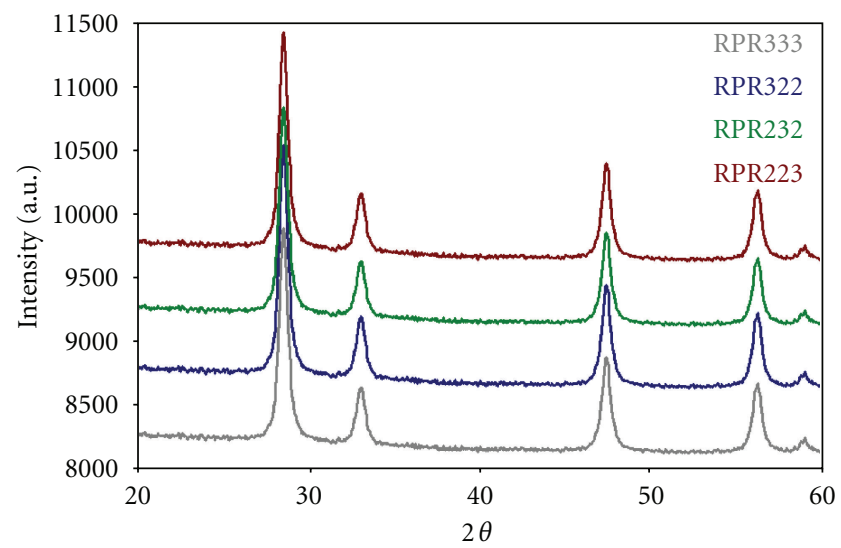

FIgURE 5: Comparative postsulfidation XRD patterns of the trimetal-supported catalysts after exposure to $1000 \mathrm{ppm} \mathrm{H}_{2} \mathrm{~S} / \mathrm{bal} . \mathrm{N}_{2}$ stream at $800^{\circ} \mathrm{C}$ for 24 hours.

The peak sharpening is an indication of systematic crystallinity enhancement as a function of time at high temperature. In this case, the peak narrowing is an artifact of grain growth and crystallite size enhancement upon sulfidation. This corroborates the statement made above with respect to the microstructural features seen in Figure 4. Moreover, the crystallite texture is maintained; the crystallite size calculation and TEM images suggest that the grain growth in the sulfided samples is only minimal, indicating that no significant surface area reduction occurred. It can also be seen that no new phases could be discerned, suggesting that phase integrity was preserved in all the formulations under sulfidation at high temperatures.

However, neither the observed grain growth nor the agglomeration adversely affected their reforming performance, as was clearly seen in terms of hydrogen yield or life-time of these formulations on-stream, as discussed in the following section. 
TABLE 1: TPR characteristics of the catalysts.

\begin{tabular}{|c|c|c|c|c|}
\hline \multirow{2}{*}{ Catalyst } & \multicolumn{3}{|c|}{ Noble metal dispersion } & \multirow{2}{*}{ Total $\mathrm{H}_{2}$ uptake for activation $(\mathrm{mL})$} \\
\hline & $\mathrm{Ru}$ & $\mathrm{Pd}$ & $\mathrm{Rh}$ & \\
\hline \multicolumn{5}{|c|}{ Monometallic formulations } \\
\hline $\mathrm{Ru}$ & $1 \mathrm{wt} \%$ & - & - & 21.26 \\
\hline $\mathrm{Pd}$ & - & $1 \mathrm{wt} \%$ & - & 20.09 \\
\hline $\mathrm{Rh}$ & - & - & $1 \mathrm{wt} \%$ & 22.94 \\
\hline \multicolumn{5}{|c|}{ Bimetallic formulations } \\
\hline RuPd & $1 / 2 \mathrm{wt} \%$ & $1 / 2 \mathrm{wt} \%$ & - & 22.38 \\
\hline RuRh & $1 / 2 \mathrm{wt} \%$ & - & $1 / 2 \mathrm{wt} \%$ & 23.91 \\
\hline RhPd & - & $1 / 2 \mathrm{wt} \%$ & $1 / 2 \mathrm{wt} \%$ & 23.77 \\
\hline \multicolumn{5}{|c|}{ Trimetallic formulations } \\
\hline RPR333 & $1 / 3 \mathrm{wt} \%$ & $1 / 3 \mathrm{wt} \%$ & $1 / 3 \mathrm{wt} \%$ & 23.52 \\
\hline RPR322 & $1 / 3 \mathrm{wt} \%$ & $1 / 2 \mathrm{wt} \%$ & $1 / 2 \mathrm{wt} \%$ & 31.79 \\
\hline RPR232 & $1 / 2 \mathrm{wt} \%$ & $1 / 3 \mathrm{wt} \%$ & $1 / 2 \mathrm{wt} \%$ & 31.98 \\
\hline RPR223 & $1 / 2 \mathrm{wt} \%$ & $1 / 2 \mathrm{wt} \%$ & $1 / 3 \mathrm{wt} \%$ & 30.92 \\
\hline
\end{tabular}

TABle 2: Performance summary of the mono-, bi-, and tri-metal supported catalysts.

\begin{tabular}{|c|c|c|c|c|c|c|c|c|c|c|}
\hline \multirow{2}{*}{ Catalyst } & \multicolumn{3}{|c|}{ Monometallic } & \multicolumn{3}{|c|}{ BiMetallic } & \multicolumn{4}{|c|}{ TriMetallic (RPR) } \\
\hline & $\mathrm{Ru}$ & $\mathrm{Pd}$ & $\mathrm{Rh}$ & RuPd & RuRh & RhPd & 333 & 322 & 232 & 223 \\
\hline Max. $\mathrm{H}_{2}$ yield $(\%)$ & 79 & 84.4 & 87 & 86 & 88 & 89 & 78.3 & 82.5 & 89.1 & 84.5 \\
\hline Duration (h) of steady level $\mathrm{H}_{2}$ yield & 51 & - & 55 & 68 & 88 & 75 & 86 & 92 & 109 & 89 \\
\hline Time (h) to deactivate to $20 \% \mathrm{H}_{2}$ & 66 & 59 & 68 & 92 & 114 & 96 & 102 & 123 & 129 & 106 \\
\hline
\end{tabular}

3.5. Steam-Reforming Characteristics. All kerosene steamreforming experiments were carried out at $800^{\circ} \mathrm{C}$ and atmospheric pressure $(\sim 14.7 \mathrm{psi})$ keeping the steam-to-carbon ratio constant at 3.0. The experiments were terminated when the hydrogen yield reached about $20 \%$ or the sulfur $\left(\right.$ as $\left.\mathrm{H}_{2} \mathrm{~S}\right)$ in the reformate stream peaked to about $50 \mathrm{ppm}$.

Figures 6(a)-6(d) depict the reformate gas compositions resulting from the steam reforming of kerosene on four trimetal-supported reforming catalysts, as a function of time on-stream.

Three outstanding features of Figure 6 are worthmentioning. First, the hydrogen yield with trimetallic formulations is higher than that obtained with the monoor bi-metal analogs. Second, the performance in terms of the duration over which hydrogen production was steady was superior. Finally, the time taken by the catalysts in the tri-metal series to deactivate (gauged by the decline in $\mathrm{H}_{2}$ concentration in the reformate to $20 \%$ or below) was also progressively longer than that in the case of bi- or monometal analogs. These can be readily discerned from the data summarized in Table 2. Interestingly, the performance in terms of hydrogen yield is characteristic of the precious metal combination in each of the four formulations.

In order to understand the synergy of the noble metals in the trimetallic formulations (specifically their sulfur tolerance), the time dependence of $\mathrm{H}_{2}$ yield in each case is shown in Figure 7.

Since kerosene contains $260 \mathrm{ppm}$ of sulfur, it is imperative to understand the difference in performance of these catalysts in terms of their behavior towards sulfur as well. For that purpose, the sulfur level (as $\left.\mathrm{H}_{2} \mathrm{~S}\right)$ in the exit stream was also monitored. The $\mathrm{H}_{2} \mathrm{~S}$ concentration profile as a function of time on-stream is shown in Figure 8.

Several interesting aspects emerge. For RPR333 (1/3 wt $\%$ $\mathrm{Ru}+1 / 3 \mathrm{wt} \% \mathrm{Pd}+1 / 3 \mathrm{wt} \% \mathrm{Rh})$ and RPR223 (1/2 wt $\% \mathrm{Ru}$ $+1 / 2 \mathrm{wt} \% \mathrm{Pd}+1 / 3 \mathrm{wt} \% \mathrm{Rh})$ the steady-state duration was 86 and 89 hours, respectively. They also exhibited relatively higher levels of sulfur in the exit stream. The marginally higher on-stream stability of RPR223 could be attributed to the elevated level of ruthenium in it, compared to that in RPR333 formulation. At the same time, lower level of rhodium $(1 / 3 \mathrm{wt} \%)$ in these two formulations could be the reason for somewhat lower $\mathrm{H}_{2}$ yield too: $78.3 \%$ for RPR333 and $84.5 \%$ for RPR223. This speculation is strengthened by the fact that the formulations with higher rhodium content generally exhibited significantly longer steady-state regime: 92 hours for RPR322 and 109 hours for RPR232-both contain $1 / 2 \mathrm{wt} \% \mathrm{Rh}$.

Furthermore, it may be recalled that in the bimetallic series, RuRh performed the best, which again contains $1 / 2 \mathrm{wt} \% \mathrm{Rh}$ [3]. Interestingly RPR 232 is essentially RuRh $(1 / 2 \mathrm{wt} \% \mathrm{Ru}+1 / 2 \mathrm{wt} \% \mathrm{Rh})$ with the addition of $1 / 3 \mathrm{wt} \%$ of Pd. Thus intuitively, RPR232 should outperform all the other formulations in the trimetallic series. This turned out to be the case, as seen from the data presented in Figures 7 and 8. In the case of RPR232, the performance was optimal: the steady-state duration increased from 88 hours for RuRh to 109 hours in the case of RPR232. The equilibrium sulfur level in the case of RPR232 was also quite low, suggesting that the incorporation of palladium helped in accentuating the sulfur 


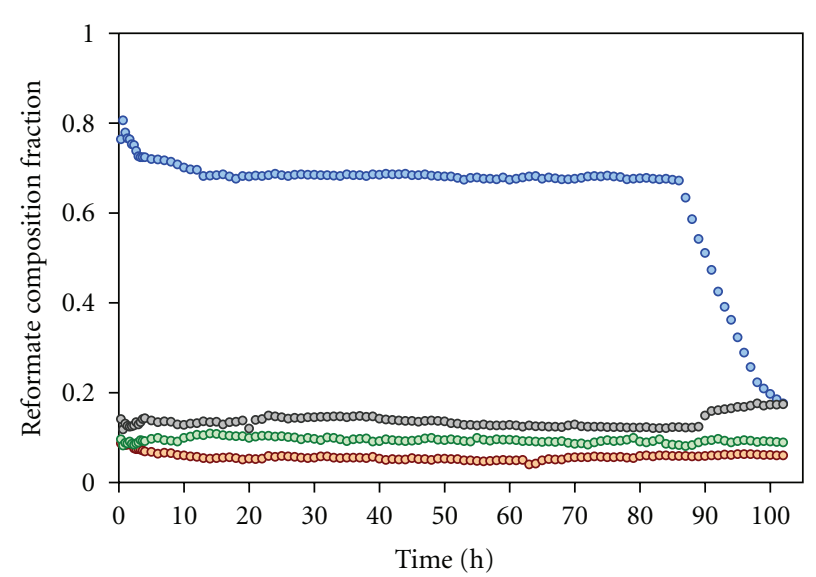

(a)

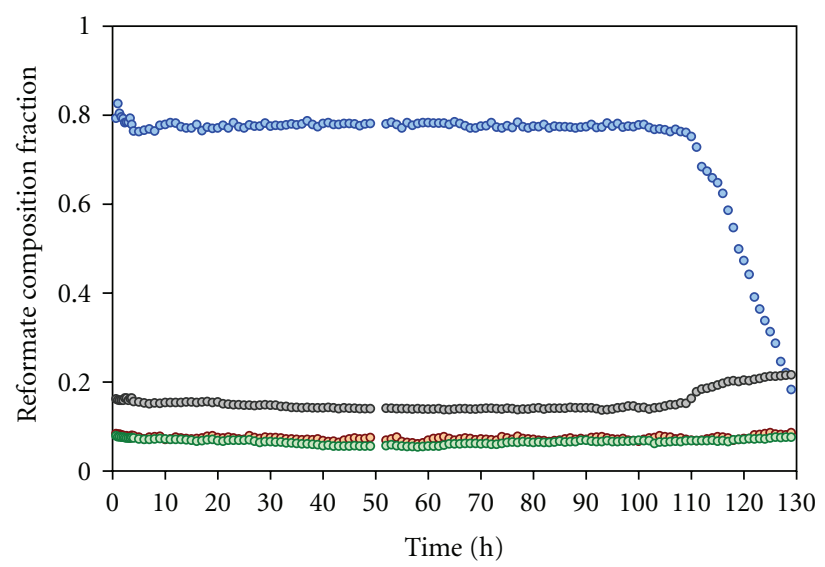

- $\mathrm{H}_{2}$

○ $\mathrm{CO}$

- $\mathrm{CH}_{4}$

- $\mathrm{CO}_{2}$

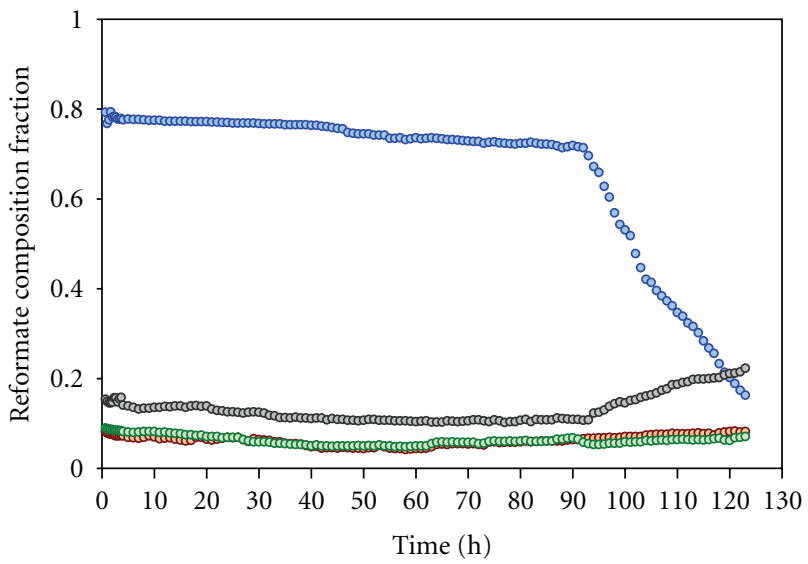

(b)

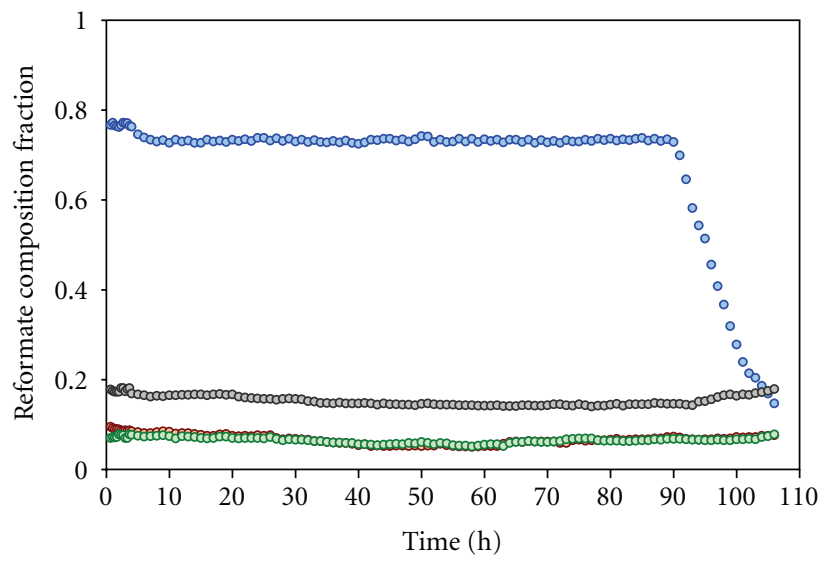

- $\mathrm{H}_{2}$

○ $\mathrm{CO}$

- $\mathrm{CH}_{4}$

- $\mathrm{CO}_{2}$

(c)

(d)

Figure 6: Composition of the reformates with: (a) RPR333, (b) RPR322, (c) RPR232 and (d) RPR223.

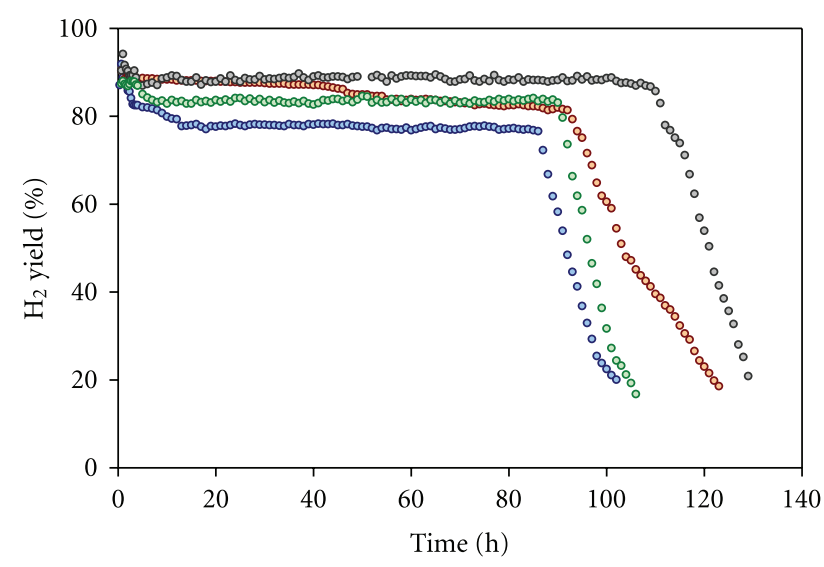
- RPR333
- RPR322
- RPR232
- RPR223

Figure 7: Performance of tri-metallic catalysts in terms of hydrogen yield. 


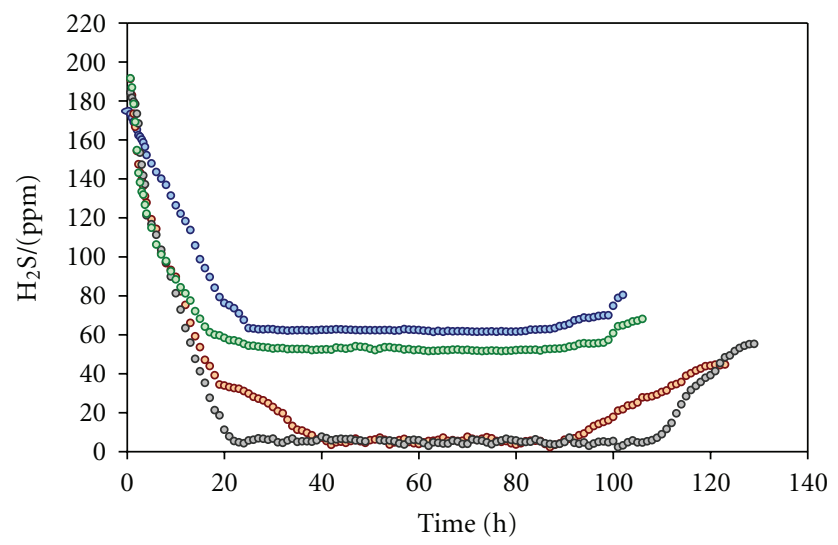

$\begin{array}{ll}\circ & R P R 333 \\ \circ & R P R 322 \\ \circ & R P R 232 \\ \circ & R P R 223\end{array}$

Figure 8: Trend in $\mathrm{H}_{2} \mathrm{~S}$ concentration profile for trimetallic catalysts with time on-stream.

pick-up by GDC, thereby making ruthenium and rhodium more facile to perform at their best in reforming, resulting in higher hydrogen yield. As a combination of these features, RPR232 also took the longest to deactivate.

Figures 9(a)-9(d) shows, the TEM images of the postreformed trimetallic catalysts.

Besides the expected peak sharpening (due to prolonged exposure to the fuel + steam on-stream) nothing unusual could be discerned from the XRD patterns of the postreformed bimetallic catalysts as they remain identical to those for as-prepared and the sulfided ones. They are also similar to those for the postreformed monometallic catalysts reported elsewhere [2]. No new phases could be identified suggesting good phase integrity of the catalysts. Calculation from the peak width showed that the grain growth in these cases was also nominal.

The XRD patterns (not shown here) and the TEM images of the postreformed samples show crystalline phases and anticipated grain growth similar to those seen in the case of postreformed mono- and bimetallic catalysts. The TEM images also show signs of slight agglomeration in the GDC support. However, as seen in the previous cases, neither grain growth nor particle agglomeration compromised the noble metal dispersion in the catalysts. The superior sulfur tolerance and reforming performance clearly suggest that there is no inferiorization of the performance due to the observed microstructural artifacts. This distinctive behavior of the tri-metal-supported ceria formulations with regard to their tolerance to sulfur in a real logistic fuel such as kerosene has been studied in such a systematic fashion perhaps for the first time.

Some salient features of the trimetallic series catalysts are as follows:

(i) RPR232 (bimetallic RuRh nominally doped with $1 / 3 \mathrm{wt} \% \mathrm{Pd}$ ) resulted in significant increment in the duration of steady $\mathrm{H}_{2}$ production. (ii) RPR232 also resulted in the reduction in the overall $\mathrm{H}_{2} \mathrm{~S}$ concentration $(<10 \mathrm{ppm})$ in the reformate, making it the best formulation in the trimetallic series.

(iii) Performance enhancement shown by the trimetallic formulations reinforces the synergistic mechanism of various noble metals towards one another in fuel reforming.

From the foregoing discussions it is apparent that there exists a definite undeniable synergistic correlation between the behaviors of various noble metals when present together. In order to understand this aspect, one could invoke stepwise sulfidation of various components of the catalyst, which is in line with the observed reforming behavior in these materials and discussed in ample detail in previous publications $[2,3]$. The primary sulfur tolerance of the family of catalysts developed in this and previous work comes from the excellent sulfurizability aspect of the host matrix, namely, ceria. The noble metal(s) sulfidation then ensues, progresses, and attains completion in the steady-state regime of hydrogen production in high yield. At the end of this period, the sulfidation of the noble metal(s) is complete, beyond which sulfur level in the reformate stream rises with a concomitant decline in hydrogen yield.

The systematic improvement in the sulfur-tolerance, fuel reformability, and length of the steady-state duration as one goes from mono- to bi- to tri-metal-supported catalysts is indicative of the cooperative phenomenon operating in the case of multicomponent (in terms of precious metals) systems. In the case of bimetallic formulations, we explained this by invoking two mechanisms: preferential sulfurizability of one precious metal in comparison to other and the sulfur spill-over, in addition to the activation and initiation mechanisms identical to those elaborated in the case of monometallic catalysts [2]. Thus, the increase in the duration of steady state (during which the hydrogen yield remains high and sulfur level low) could be explained in the 


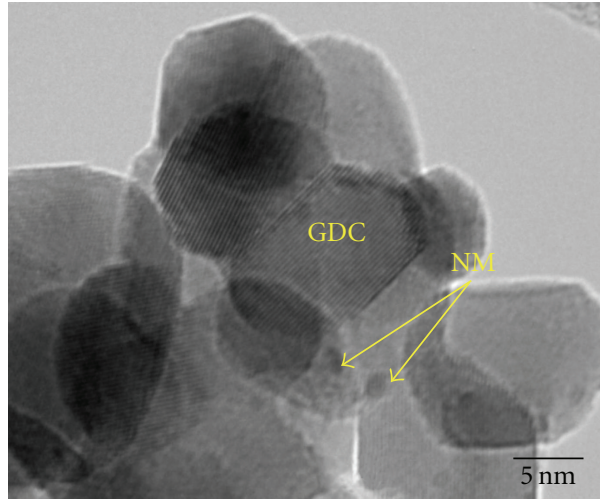

(a)

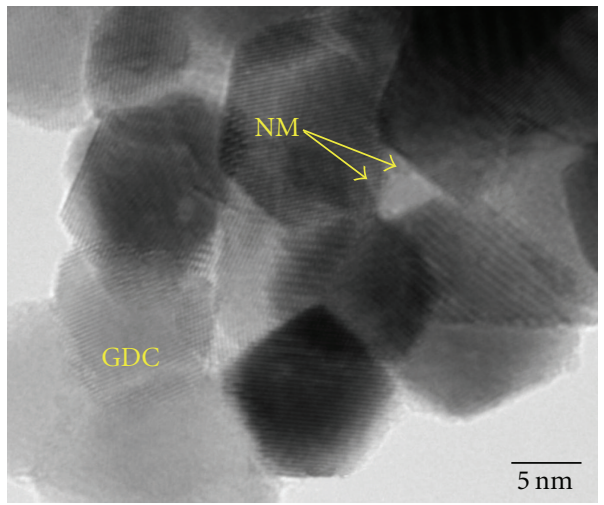

(c)

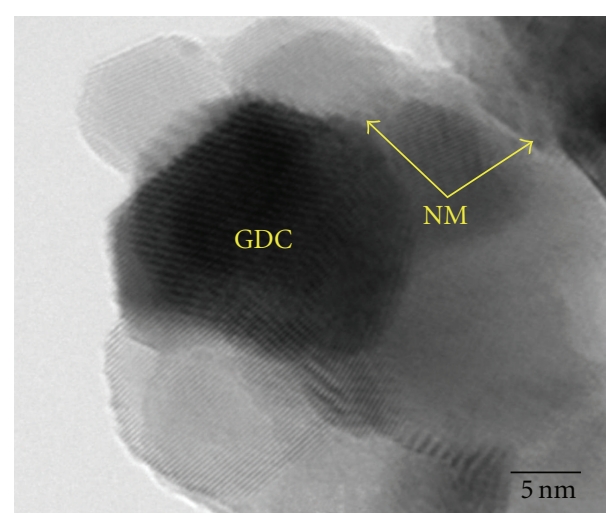

(b)

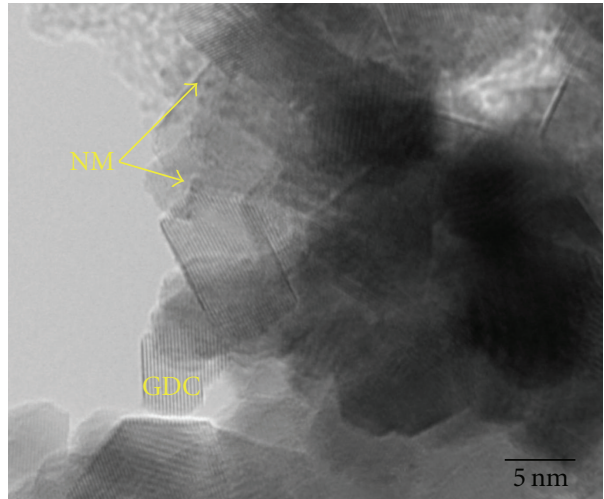

(d)

FiguRE 9: TEM image of the postreformed catalysts in the tri-metal series: (a) RPR333, (b) RPR322, (c) RPR232, and (d) RPR223.

light of preferential sulfur pick-up by one noble metal followed by the transfer of sulfur to more sulfur susceptible counterpart.

This scheme is shown as a multistage process in Figure 10 in the case of tri-metal-supported ceria formulations.

The first aspect in a bi-metal system is a result of better dispersion while the second aspect arises from the cooperative synergy between the two metals when exposed to identical chemical environment. This ability, NM1 to pass the sulfur onto the more readily sulfurizable NM2, allows the catalyst as a whole to remain active for a longer period of time. Thus, it is safe to assume that a sulfur "spill-over" mechanism is operative in the case of bimetallic (NM1 + NM2) series. Under this mechanism, in the steady-state regime one of the two noble metals undergoes sulfidation first. At some point during this process, the sulfided metal begins transferring sulfur via "spill-over" mechanism to the second metal which begins to then sulfide, allowing the first metal to remain active in reforming. Deactivation sets in when the second metal is completely sulfided and the more active one begins sulfiding. Due to sulfur pick-up by both the active metals in the catalyst, sulfur level in the exit drops, and eventually when both metals are completely sulfided, the catalyst begins to deactivate, sulfur reemerges in the exit, and hydrogen production declines. In the light of this, it could be seen that a bimetallic formulation could be very effective as a more sulfur-tolerant reforming catalyst compared to its monometal counterpart. This mechanistic picture is in total conformity with the experimental results discussed above, where clear evidence of superior reforming performance and sulfur tolerance of the bimetallic catalysts over their monometallic analogs was seen.

The above scheme could be extended to the trimetallic series as well. In this case, however, the cooperative synergy is further accentuated, resulting in even higher sulfur tolerance, still better hydrogen yield, and significantly longer span of stead-state compared to any of the mono- or bimetal series. Addition of a third precious metal, even in as small a weight fraction as $1 / 3$ of $1 \%$, to a bi-metallic formulation improvised the sulfur tolerance and reforming behavior significantly. In this case as well, systematic sulfidation of the noble metals occurs in the steady-state regime. If the noble metals in the catalysts were to sulfide simultaneously, the catalyst would undergo deactivation rather quickly and hydrogen yield would decline immediately. On the contrary, the tri-metal-supported catalysts remain active for a prolonged duration during which the hydrogen yield remains fairly high and almost constant. This experimental evidence could be explained if sulfur "spill-over" mechanism is invoked again, akin to that in bimetallic series. In this 


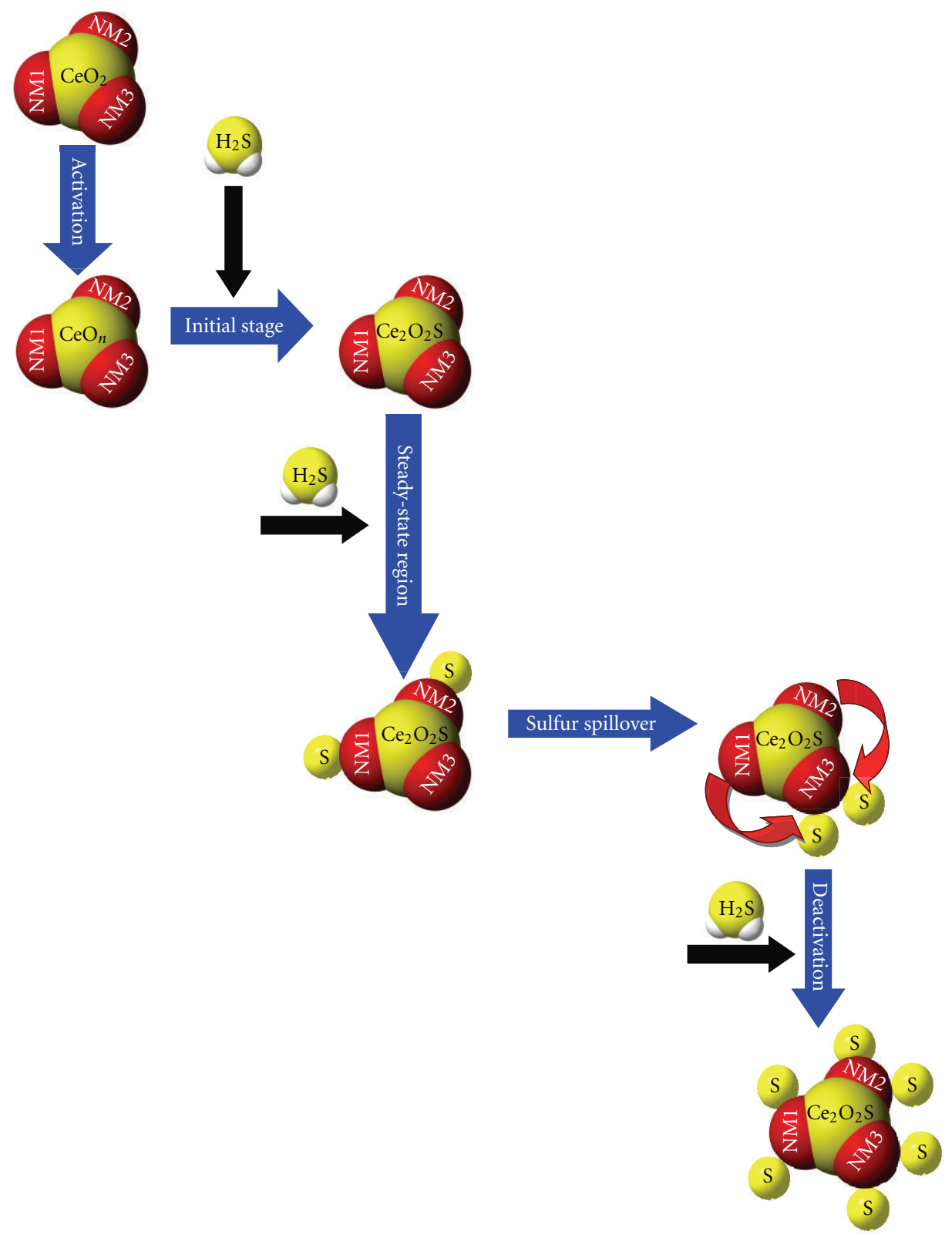

FIgURE 10: Phenomenological mechanism operative in the tri-metal-supported catalysts.

case, the initial successive sulfidation of the two of the three noble metals (NM1 and NM2) is followed by the sulfur spillover to NM3 with higher sulfur affinity. This spares NM1 and NM2 to remain unsulfided and active to perform the reforming process. Once NM3 is fully sulfided, NM1 and NM2 begin to pick-up sulfur from the stream. At this stage, deactivation sets in. Upon completely sulfidation of all the three precious metals, the sulfur level in the exit reemerges with a concomitant decrease in hydrogen yield.

The proposed mechanism is in complete agreement with the observed behavior in the sulfidation as well as reforming experiments over extended periods of time. It explains the role of noble metals-individually as well as in combination with others-in the reforming of sulfur-laden fuels. It also provides a good rationale for synergistic behavior of noble metals in the case of bi- and trimetallic catalyst formulations.

\section{Conclusion}

A new family of high performance nanocatalysts containing three precious metals highly dispersed on gadolinia-doped ceria support has been developed and systematically characterized with respect to their structural, microstructural and sulfur-tolerance aspects. Loading of the precious metals was varied systematically such that their combined total in the formulations did not exceed $1.33 \mathrm{wt} \%$. Steam-reforming of 
kerosene at $800^{\circ} \mathrm{C}$ and atmospheric pressure with steam-tocarbon (S/C) ratio equal to 3.0 on these formulations produced hydrogen-rich reformates over long durations before deactivation sets in, which is rather slow and monotonic than sudden and precipitous. The difference in the behavior of various formulations is explained in terms of the inherent ability of the ceria support to pick-up sulfur together with the sulfidation propensity of the precious metals dispersed on ceria. In presence of one another, the precious metals exhibit cooperative synergy which is the reason behind excellent performance of these formulations. The catalyst deactivation appears due mainly to the sulfur poisoning rather than carburization (coke formation) based on the absence of noticeable level of elemental carbon in highresolution microscopic images in the postreformed samples.

\section{References}

[1] Y. Lu, J. Chen, Y. Liu, Q. Xue, and M. He, "Highly sulfurtolerant $\mathrm{Pt} / \mathrm{Ce}_{0.8} \mathrm{Gd}_{0.2} \mathrm{O}_{1.9}$ catalyst for steam reforming of liquid hydrocarbons in fuel cell applications," Journal of Catalysis, vol. 254, no. 1, pp. 39-48, 2008.

[2] A.-M. Azad and D. Sundararajan, "A phenomenological study on the synergistic role of precious metals and the support in the steam reforming of logistic fuels on monometal supported catalysts," Advances in Materials Science and Engineering, vol. 2010, Article ID 681574, 15 pages, 2010.

[3] A.-M. Azad and D. Sundararajan, "A phenomenological study on the synergistic role of precious metals in the steam reforming of logistic fuels on bi-metal supported catalysts," submitted to Fuel.

[4] A. Trovarelli, Ed., Catalysis by Ceria and Related Materials, vol. 2, Imperial College Press, London, UK, 2002.

[5] Handbook of Aviation Fuel Properties, Coordinating Research Council, Atlanta, Ga, USA, 1983.

[6] M. Mogensen, N. M. Sammes, and G. A. Tompsett, "Physical, chemical and electrochemical properties of pure and doped ceria," Solid State Ionics, vol. 129, no. 1, pp. 63-94, 2000.

[7] M. Funabiki, T. Yamada, and K. Kayano, "Auto exhaust catalysts," Catalysis Today, vol. 10, no. 1, pp. 33-43, 1991.

[8] S. Tagliaferri, R. A. Köppel, and A. Baiker, "Influence of rhodium- and ceria-promotion of automotive palladium catalyst on its catalytic behaviour under steady-state and dynamic operation," Applied Catalysis B, vol. 15, no. 3-4, pp. 159-177, 1998.

[9] A.-M. Azad and M. J. Duran, "Development of ceriasupported sulfur tolerant nanocatalysts: Rh-based formulations," Applied Catalysis A, vol. 330, no. 1-2, pp. 77-88, 2007.

[10] A.-M. Azad, M. J. Duran, A. K. McCoy, and M. A. Abraham, "Development of ceria-supported sulfur tolerant nanocatalysts: Pd-based formulations," Applied Catalysis A, vol. 332, no. 2, pp. 225-236, 2007.

[11] A. C. McCoy, M. J. Duran, A.-M. Azad, S. Chattopadhyay, and M. A. Abraham, "Performance of sulfur tolerant reforming catalysts for production of hydrogen from jet fuel simulants," Energy and Fuels, vol. 21, no. 6, pp. 3513-3519, 2007.

[12] ICDD card \# 75-0162. 

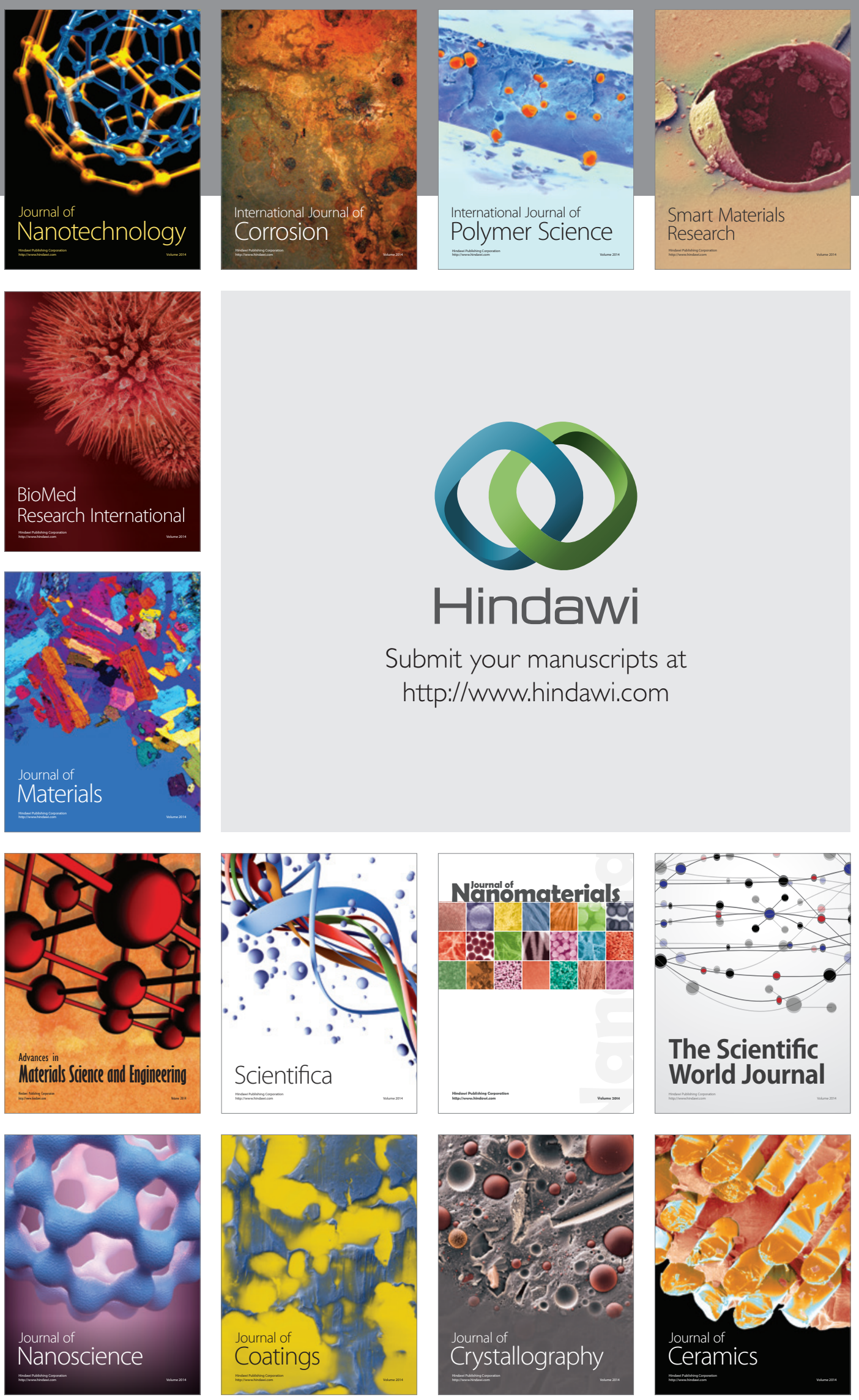

The Scientific World Journal

Submit your manuscripts at

http://www.hindawi.com

\section{World Journal}

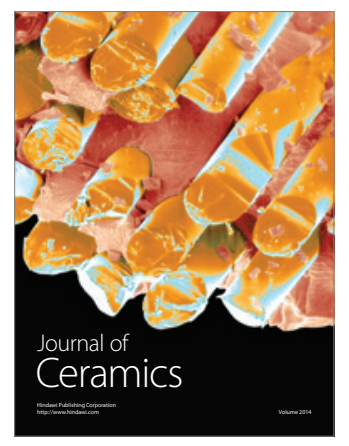

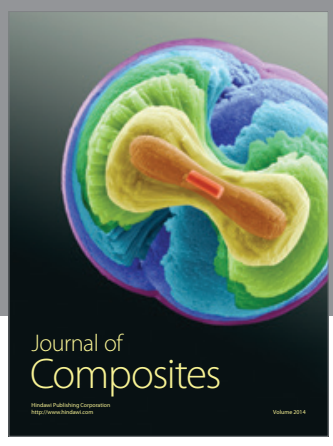
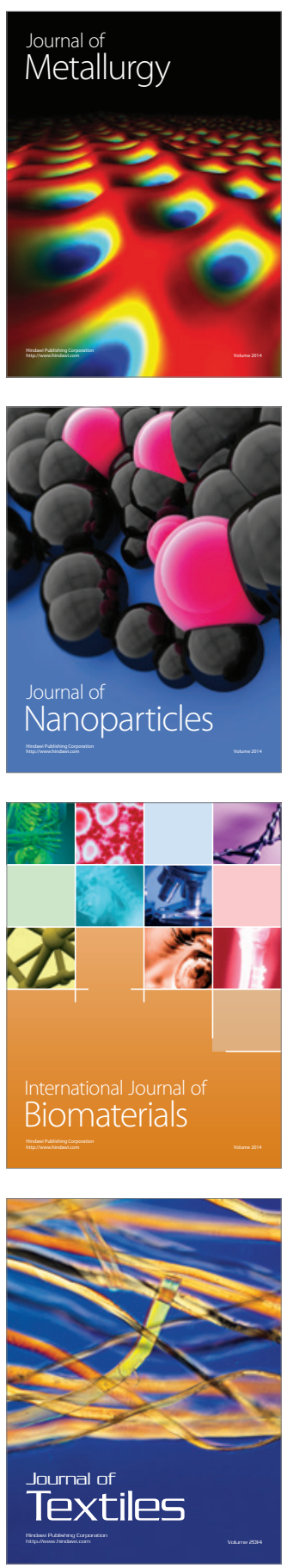